\title{
SOBRE A NATUREZA DO PRESENTE HISTÓRICO. A CRÍTICA DA DOMINAÇÃO NO INSTITUTO DE PESQUISA SOCIAL NO INÍCIO DOS ANOS 1940
}

Com a ascensão de Hitler ao poder na Alemanha em janeiro de 1933, o Instituto de Pesquisa Social de Frankfurt, depois de passar por Genebra, Paris e Londres, se encontra no exílio nos Estados Unidos em princípios da década de 1940. Em vista do contexto social, político e econômico - marcado pelo nazismo, pelo stalinismo e pelo capitalismo norte-americano -, a tentativa de elaborar uma análise e uma explicação do presente histórico ganha uma coloração de urgência para aqueles que se encontravam reunidos em torno do Instituto. ${ }^{1}$ Em 1941, a efervescência intelectual que a situação suscita se expressa "numa série de conferências sobre o nacional-socialismo" (González, 1992: 147), organizadas pelo Instituto na Universidade de Columbia, ${ }^{2}$ e em publicações que aparecem nesse ano e no ano seguinte. Se alguns pontos básicos do diagnóstico sobre o nazismo efetuado por diferentes associados coincidiam em dada medida - como o fato de ele constituir "uma reação política apoiada pelos interesses do grande capital" e ser "herdeiro da crise histórica do liberalismo" -, na avaliação da "natureza político-econômica do novo regime" se revelavam claramente as divergências (González, 1992: 147).

Em si mesmos, os debates de Columbia se revestem de importância tanto para a história intelectual da teoria crítica da assim chamada Escola de Frankfurt (contando com a participação desde associados hoje mais conhecidos até outros menos célebres) como também, de forma mais ampla, para a reconstrução das interpretações sobre o nacional-socialismo que ti- 
veram lugar concomitantemente ao próprio desenrolar do fenômeno. Além disso, as discussões sobre como caracterizar o estágio pelo qual passava o capitalismo podem ser vistas como uma antessala da Dialética do esclarecimento, que Theodor Adorno e Max Horkheimer concluíram em 1944 e publicaram em 1947, no sentido de que a empreitada que esse livro leva a cabo é, em boa medida, uma resposta, original e própria, ao debate que vinha ocupando os associados ao Instituto. Os resultados alcançados por diferentes membros do Instituto de Pesquisa Social nesse período podem ser vistos como pontos altos das análises do presente histórico da Escola de Frankfurt e permanecem como um referencial de grande envergadura para a teoria social. O artigo procura reconstruir os posicionamentos dos conferencistas em Columbia e, em seguida, busca mobilizar alguns elementos para interpretar a crítica civilizatória que a Dialética do esclarecimento apresenta e que é encarada como um desfecho que responde, em outro registro, às indagações sobre a natureza do presente histórico.

\section{POLLOCK E O CAPITALISMO DE ESTADO}

No artigo "Capitalismo de Estado: suas possibilidades e limitações”, incluído no número de 1941 da Studies in Philosophy and Social Science, ${ }^{3}$ Pollock tem como uma de suas hipóteses básicas a de que o "livre comércio e a livre empresa do século 19 estão saindo de cena" (Pollock, 1941a: 200). Desde ao menos o pós-Primeira Guerra Mundial, a "empresa privada de médio porte e o livre comércio, bases para o gigantesco desenvolvimento das forças produtivas dos homens no século 19, estão sendo gradualmente destruídas pela descendência do liberalismo: monopólios privados e interferência governamental" (Pollock, 1941a: 202). Pollock interpreta os "desenvolvimentos sociais e econômicos na Europa desde o fim da Primeira Guerra Mundial" como "processos de transição transformando o capitalismo privado em capitalismo de Estado" (Pollock, 1941a: 200). No início do texto, Pollock diz que o termo capitalismo de Estado se refere a um modelo, construído a partir de "elementos há muito visíveis na Europa e, em certa medida, até mesmo na América", e que entende modelo no sentido de um tipo ideal weberiano (Pollock, 1941a: 200). ${ }^{4} \mathrm{O}$ modelo do capitalismo de Estado é definido por Pollock levando em conta duas variedades típicas mais importantes: a forma totalitária e a forma democrática. O nazismo é o protótipo da primeira e as potências democráticas o da segunda. Entre esses dois extremos, entretanto, pode existir uma variedade de formas. A tentativa de Pollock de construir um modelo de capitalismo de Estado se baseia quase que inteiramente na vertente totalitária - em especial tendo por referência a Alemanha nacional-socialista -, e a justificativa apresentada para tal é que o sistema capitalista de Estado se encontra 
ainda num estágio incipiente no mundo democrático. Dado que Pollock aponta o capitalismo de Estado como uma tendência, a aposta de que a forma democrática prevaleça sobre a totalitária fica saliente em sua argumentação. ${ }^{5}$

Para Pollock, a expressão capitalismo de Estado indica quatro pontos: (1) ele é sucessor do capitalismo privado, (2) o Estado assume funções antes a cargo dos capitalistas privados, (3) a motivação do lucro ainda é significativa e, por fim, (4) não se trata de socialismo (ver Pollock, 1941a: 201). O desenvolvimento, diagnosticado por Pollock àquela altura, de toda uma sorte de regulações por parte do aparato governamental, tanto nos regimes políticos autoritários da Europa quanto nos Estados Unidos, o faz concluir que a coordenação da produção e da distribuição passa a se dar com a interferência de formas de controle direto por parte dos governos. Esses instrumentos de controle compreendem a operação de um pseudomercado e a manutenção do pleno emprego de todos os recursos. "Com o mercado autônomo, as assim chamadas leis econômicas desaparecem”, escreve o autor (Pollock, 1941a: 201). A etapa do capitalismo de Estado tem como características distintivas a planificação econômica, o controle governamental dos preços, a subordinação do interesse individual ao coletivo, a administração científica das atividades e a politização dos problemas econômicos. Conforme Pollock, trata-se de uma combinação de "velhos e novos instrumentos" (Pollock, 1941a: 200). O resultado é a passagem do capitalismo monopolista para o capitalismo de Estado, que significa a emergência de um novo ordenamento econômico: "todos os conceitos e instituições básicos do capitalismo tiveram sua função alterada; a interferência do Estado na estrutura da velha ordem econômica, em virtude de seu caráter total e de sua intensidade, 'converteu a quantidade em qualidade', transformou o capitalismo monopolista em capitalismo de Estado" (Pollock, 1941b: 445). ${ }^{6}$ Se antes os monopólios eram "agentes perturbadores", agora eles "assumem o controle das funções de mercado como agentes governamentais" (Pollock, 1941b: 451).

O processo econômico passa a contar com o "princípio do planejamento", expresso em um "plano geral [que] dá a direção para a produção, o consumo, a poupança e o investimento" (Pollock, 1941a: 204). Disso se depreende o maior peso atribuído por Pollock à decisão política do que à necessidade intrinsecamente econômica: "O verdadeiro problema de uma sociedade planejada não está na esfera econômica, e sim na política [...]" (Pollock, 1941a: 204). Em decorrência do planejamento econômico, no capitalismo de Estado os preços perdem sua função clássica de balizar e guiar os investimentos entre as esferas de produção, e os "preços administrados" se tornam não mais do que "um dispositivo suplementar para incorporar a produção e o consumo ao plano geral" (Pollock, 1941a: 204). Essa característica central do capitalismo de Estado, uma espécie de sobreposição da "esfera econômica pela política" (Postone \& Brick, 1993: 219), queria dizer, para Pollock, que a 
primeira tinha se tornado administrável pela segunda (ver Postone \& Brick, 1982: 623). Na fase do capitalismo de Estado, em "todas as esferas da atividade do Estado (e, sob o capitalismo de Estado, isso quer dizer em todas as esferas da vida social como um todo) a suposição [guesswork] e a improvisação dão lugar aos princípios da administração científica [scientific management]" (Pollock, 1941a: 206).

Com isso, Pollock levanta a polêmica tese de que as restrições ou limites de um sistema assim configurado são mais de ordem natural do que econômica, além daquelas que provêm da "própria estrutura da sociedade" (Pollock, 1941b: 455; ver, também, Pollock, 1941a: 217), isto é, do inconformismo em relação a um regime totalitário que, mesmo que proveja o necessário à sobrevivência material, não concede liberdade a seus cidadãos. Com os instrumentos dos quais faz uso - administração de preços objetivando regular o balanço entre produção e distribuição de bens, garantia do pleno emprego por meio da produção de obras públicas, expansão do aparato militar como um caminho para contornar a superacumulação -, o capitalismo de Estado minora as possibilidades de crise econômica. Já em um texto na primeira edição da Zeitschrift für Sozialforschung, em 1932, Pollock havia apontado para as "perspectivas de se chegar a uma economia capitalista estável" (Jay, 2008: 206). ${ }^{7}$

Pollock afirma que o verdadeiro sentido da ideologia Gemeinnutz geht vor Eigennutz (o benefício geral vem antes do benefício próprio) encontra seu lugar na subordinação dos interesses individuais, grupais e parciais na obtenção de lucro ao plano geral (ver Pollock, 1941a: 205). Esse plano geral expressa os desígnios da nova classe dominante, composta de quatro grupos: os grandes negócios, o partido vitorioso, a burocracia estatal e o exército. Possuindo interesses conflitantes, eles são, entretanto, guiados por objetivos comuns. Os acordos e compromissos entre os grupos dominantes determinam os rumos a serem tomados pelo processo econômico. E todo aquele "que não pertence a esse grupo é um mero objeto da dominação" (Pollock, 1941a: 201). Um dos principais logros obtidos pelo sistema de planejamento, a segurança econômica, cumpre, segundo Pollock, uma eficaz função de integração social, contribuindo para perpetuar a dominação dos governantes sobre os governados. ${ }^{8}$ No capitalismo de Estado, em especial nos regimes autoritários de capitalismo de Estado, se evidencia um incremento da dominação social, em função da ampliação do escopo da racionalidade técnica. "A maior preocupação do governo é a precisão e a velocidade com a qual suas ordens em constante mudança são executadas. Sob um tal sistema, os órgãos executivos tendem a ser cada vez mais semelhantes a máquinas [machinelike], e essa qualidade de máquina confere ao aparato estatal seu alto grau de precisão e calculabilidade técnica" (Pollock, 1941b: 448). O indivíduo é reduzido mais e mais a substrato da dominação e os resquícios de autonomia, ainda existen- 
tes na era burguesa, são aniquilados. O sistema de comando que substitui o mercado e integra economicamente as massas por meio do pleno emprego tem seu correlato sociopolítico na transformação do status do indivíduo e da família, e o conjunto dessas transformações sinaliza que "uma nova ordem está se constituindo, uma nova ordem política, legal, econômica e social" (Pollock, 1941b: 449).

\section{NEUMANN E O CAPITALISMO MONOPOLISTA TOTALITÁRIO}

O livro Behemoth, de Franz Neumann, apareceu pela primeira vez em 1942, tendo sido depois lançada, em 1944, uma edição revista. Em Behemoth, Neumann leva a cabo uma longa análise sobre a política, a economia e a estrutura social da Alemanha nazista. Para o autor, a "tendência crescente a negar o caráter capitalista do nacional-socialismo", na qual estaria incluída a tese do capitalismo de Estado, é errônea (Neumann, 2009: 222). Neumann defende que, durante o período da República de Weimar, a política de compromisso social-democrata inadvertidamente fortaleceu as tendências monopolistas da economia alemã, a ponto de os maiores conglomerados econômicos já vistos na história alemã terem se formado nessa época. Todavia, mesmo que na prática o regime democrático de Weimar não bloqueasse tal desenvolvimento, o "perigo para os privilégios inerente à democracia política permanecia”, ou seja, pairava sempre a ameaça de que a livre evolução dos monopólios pudesse ser controlada ou freada (Neumann, 2009: 16) - a pressão pública forçou o governo a promulgar um decreto em novembro de 1923 visando restringir cartéis e monopólios, mas esses poderes nunca foram usados.

O nacional-socialismo que vem dar fim a Weimar, por outro lado, se afigura nesse cenário como fiador político dos processos monopólicos da economia, trazendo à "sua conclusão lógica um desenvolvimento iniciado há muitas décadas, nomeadamente, que a organização da indústria em cartéis é uma forma melhor e mais elevada de organização industrial" (Neumann, 2009: 266). Neumann argumenta que os "objetivos dos poderes monopolistas não podiam ser levados adiante num sistema de democracia política, ao menos não na Alemanha" (Neumann, 2009: 260). A dinâmica interna do aparato industrial monopolista alemão em expansão apontava para a necessidade de um alargamento de seus mercados externos, de modo a poder garantir a transferência para si de mais trabalho em troca de menos trabalho. O ímpeto econômico expansionista da Alemanha tinha sua contraparte lógica na expansão territorial. Mas como latecomer no clube das potências industriais, ela encontrou o mundo já dividido pelas nações de industrialização mais antiga. A conquista de mercados não poderia ocorrer de forma pacífica. ${ }^{9} \mathrm{~A}$ despeito de assinalar que o nazismo não podia ser reduzido a um instrumento da grande 
indústria, Neumann frisa que o expansionismo imperialista era um ponto em relação ao qual a indústria e o Partido Nacional-Socialista tinham objetivos idênticos. O nacional-socialismo mobiliza a ideologia da superioridade racial alemã, já profundamente enraizada no pensamento alemão (ver Neumann, 2009: 102-111), para justificar o expansionismo e o imperialismo.

Na fase do capitalismo monopolista, a cartelização e a monopolização "não são a negação da competição, mas uma outra forma dela", ou, dialeticamente falando, "longe de negar a competição, os cartéis a afirmam" (Neumann, 2009: 291-292). Pois o "poder que motiva a expansão é o lucro. A estrutura da economia alemã é a de uma economia completamente monopolizada e cartelizada" (Neumann, 2009: 292). Neumann afirma que o processo de monopolização na Alemanha resulta de profundas mudanças tecnológicas ocorridas a partir dos anos 1930, tendo por base o desenvolvimento do ramo químico. Essas inovações surgiram no âmbito do próprio mecanismo capitalista de produção, fato que, na ótica de Neumann, permite refutar a tese da perda de dinamismo do capitalismo. O que mais bem ocorreria é que, dados os altos investimentos por elas requeridos, o apoio do Estado se torna indispensável, sem que este, porém, tome para si a condução da economia. No que tange à obtenção privada de lucro, o sistema nacional-socialista impede que essa consecução seja dificultada, como poderia ocorrer num sistema político democrático que interpusesse barreiras ao avanço da monopolização econômica. A função essencial do Estado é, portanto, encarregar-se de proteger e consolidar os grandes monopólios industriais alemães: o sistema totalitário nacional-socialista garante o domínio dos monopólios por meio da eliminação da liberdade de contrato, pelo controle sobre o mercado de trabalho e pela regulação exercida sobre a disposição de matérias-primas, sobre os preços, o comércio e o crédito.

O próprio Estado nacional-socialista, na visão de Neumann, é mais bem um não Estado, o que o faz recorrer à figura de Behemoth para dar título a seu livro. Enquanto no Leviatã Hobbes representava um poder soberano que, ainda que baseado na força, se apoia no consentimento, conta com justificação racional, não anula de todo o indivíduo e preserva vestígios do império da lei, em Behemoth or the Long Parliament ele descrevia a ausência de leis e, portanto, de Estado. Se o Estado é caracterizado pelo império da lei, então a resposta de Neumann à questão de se o sistema político da Alemanha nacional-socialista constitui um Estado é negativa. "É impossível detectar na estrutura do sistema político nacional-socialista qualquer órgão que monopolize o poder político" (Neumann, 2009: 469), diz Neumann. Pelo contrário: "Sob o nacional-socialismo, [...] a sociedade inteira está organizada em quatro grupos sólidos, centralizados, cada um deles operando sob o princípio da liderança, cada um com um poder legislativo, administrativo e judicial próprio" (Neumann, 2009: 468). Esses quatro grupos são o partido, a grande indústria, 
as forças armadas e a burocracia. Esses diferentes grupos têm os seus interesses próprios, mas são mutuamente dependentes e estabelecem entre si compromissos, tudo visando à expansão e à guerra imperialistas, das quais todos, de distintas maneiras, sacam benefícios.

A despeito de sua caracterização do Estado como um não Estado, Neumann considera que o nacional-socialismo é um sistema totalitário. A economia desse sistema totalitário, longe de ser estatizada, é uma economia monopolista privada. Entretanto, o nacional-socialismo não constitui uma forma político-econômica nova, diagnóstico que se opõe à tese do capitalismo de Estado. “O próprio termo 'capitalismo de Estado' é uma contradictio in adiecto”, assevera Neumann (2009: 224). Em linhas gerais, tanto Neumann quanto Pollock convergiam quanto à avaliação do avanço e predomínio da monopolização e de um alargado protagonismo do Estado. Mas os defensores da tese do capitalismo de Estado não teriam sido, para Neumann, capazes de demonstrar a passagem do capitalismo monopolista para o capitalismo de Estado (ver Neumann, 2009: 221-228). Neumann sustenta que o nazismo consiste numa específica configuração do capitalismo monopolista. Daí sua crítica de que a asserção acerca da emergência de um novo sistema tem que ser provada caso a caso, e não pode englobar coisas tão distintas como o nacional-socialismo, o sistema soviético e o intervencionismo estatal das democracias ocidentais.

\section{KIRCHHEIMER E A CONFIGURAÇÃO DO COMPROMISSO POLÍTICO}

Em dois textos no número IX da Studies in Philosophy and Social Science, Otto Kirchheimer procura examinar o nacional-socialismo sob a perspectiva de seus específicos arranjos jurídico-políticos. Seu enfoque destaca as formas de estabelecimento do compromisso político e a configuração do Estado na Alemanha nazista. Conforme Kirchheimer, a partir da segunda década do século 20, marcada pelo declínio da função do dinheiro como medida universal e pelo avanço do processo de monopolização, tem início o período da democracia de massas. Os pactos tendem então a "evoluir de individuais para acordos voluntários entre os principais grupos do capital e do trabalho e suas subdivisões" (Kirchheimer, 1941b: 288), dissolvendo progressivamente o tipo de compromisso que caracterizou o sistema representativo liberal. Com a transição do capitalismo competitivo para o capitalismo monopolista, o compromisso passa a ter lugar "entre grandes organizações sociais e políticas" (Kirchheimer, 1941b: 273). A concentração em grandes unidades econômicas, que avança às custas da eliminação da pequena empresa individual, se expressa nas mudanças que se dão no compromisso político.

O nacional-socialismo representa um estágio em que a posição dos grupos se consolida mediante o reconhecimento pelo Estado de que eles são 
os únicos partícipes legítimos do compromisso político. A exposição nos dois textos de Kirchheimer sublinha a redução da independência do indivíduo face aos poderes constituídos dos aparatos burocrático e monopolista e aponta que, política e juridicamente, o nazismo processa a subsunção dos indivíduos aos grupos, os quais se afirmam como os verdadeiros detentores de direitos - numa radicalização das tendências já presentes no regime de Weimar - e sujeitos da política. Na ausência de regras e procedimentos universalmente válidos que se instala, a decisão de um eventual conflito entre as partes fica por conta da discricionariedade do poder do Führer. A imagem da dissolução e mesmo inexistência de um Estado enquanto tal, assim como a aliança entre os líderes nazistas e os dirigentes monopolistas em nome do imperialismo, que emergem da análise de Kirchheimer, podem também ser pensadas em proximidade com a descrição que Neumann apresenta em seu Behemoth. Kirchheimer, semelhantemente a Neumann, caracteriza a ideologia nacional-socialista como algo cambiante, que busca se adaptar continuamente à mudança das situações.

Uma das características mais marcantes da "nova ordem legal" nacional-socialista é a reunião "do interesse da propriedade privada e da administração, da vantagem privada e dos fins públicos" (Kirchheimer, 1941b: 461-462). De forma semelhante ao que se passa na construção de Neumann, em Kirchheimer o Estado tem um papel de garantidor da ordem econômica, fomentando a concentração em cartéis e monopólios, instituindo a padronização de produtos, possibilitando à indústria a realização dos grandes investimentos requeridos pelas condições tecnológicas modernas e propiciando uma crescente segurança econômica. A partir da constatação da presença, na esfera da lei e de sua aplicação, de um tipo de racionalidade que "serve exclusivamente àqueles que governam" e cuja preocupação é, acima de tudo, responder à questão "Como um dado comando pode ser executado de modo a ter o máximo efeito no mínimo tempo possível?" (Kirchheimer, 1941b: 466), Kirchheimer destaca que tal racionalidade técnica encontrada no campo jurídico permeia também todo o organismo administrativo nacional-socialista. Assim como Pollock, Kirchheimer aproxima essa racionalidade, que visa otimizar a execução das ordens, ao "trabalho de uma boa máquina", já que o padrão que lhe serve de base é dado pela "organização da indústria" (Kirchheimer, 1941b: 466). A comunidade racial que o Terceiro Reich se esforça em construir lança mão da racionalidade calculadora quando, no plano de sua política populacional imperialista, relaxa convenções morais e converte "toda mulher numa agente oficial de procriação" (Kirchheimer, 1941b: 463) ou, no que diz respeito à perseguição aos indesejáveis, trata com "brutalidade crescente" os “criminosos inimigos do povo" (Kirchheimer, 1941b: 472).

González faz notar que, à diferença de Pollock, Neumann e Kirchheimer consideravam que "o novo regime não havia alterado em absoluto as leis 
funcionais do mercado capitalista", ou seja, que o "Estado tão somente havia assumido controles políticos adicionais de natureza totalitária" (González, 1992: 63). Coincidiam em julgar "o nacional-socialismo como um mero arcanum dominationis, um sistema que havia substituído a racionalidade procedimental por uma técnica de dominação sem dissimulação" (González, 1992: 144). Na visão de Kirchheimer e Neumann, o nacional-socialismo seria "uma forma de dominação emancipada dos compromissos jurídicos do Estado liberal", na qual "os interesses respectivos das elites do partido, dos grupos econômicos, da burocracia e do exército confluíam dependendo das condições de valorização de um capitalismo monopolista" (González, 1992: 63).

\section{GURLAND E A REVOLUÇÃO TECNOLÓGICA}

Numa nota à parte de Behemoth, que trata da economia monopolista, Neumann remete o leitor ao "excelente ensaio 'Tendências tecnológicas e estrutura econômica sob o nacional-socialismo' [...] do Dr. A. R. L. Gurland, com quem eu discuti todos os problemas dessa seção do meu livro" (Neumann, 2009: 503). Segundo Kevin Amidon e Mark Worrell, Behemoth seria o produto mais conhecido da colaboração entre Gurland e Neumann, o qual "reconhece amplamente a contribuição de Gurland para as partes econômicas do livro" (Amidon \& Worrell, 2008: 139). O texto de Gurland, ao qual Neumann se refere em sua nota, também figurou no número de 1941 da Studies in Philosophy and Social Science. Gurland se ocupa da questão da revolução tecnológica na ordem econômica da Alemanha sob Hitler. Sua posição é a de que, nas condições totalitárias da economia, o dinamismo técnico-econômico não chegou a seu termo. "Houve uma importante transformação tecnológica da produção industrial, e isso é suficiente para rejeitar a tese de que o dinamismo tecnológico chegou ao fim" (Gurland, 1941: 226), afirma Gurland. Sob o nacional-socialismo, o desenvolvimento tecnológico segue linhas já estabelecidas no período pré-totalitário e um padrão herdado dessa fase anterior. O que para Gurland salta aos olhos como propulsor daquilo que chama de revolução tecnológica são as mudanças e avanços nos processos da indústria química vale lembrar que Neumann toma essas inovações como centrais em sua caracterização da economia monopolista.

Gurland aponta que, já antes de 1933, a estrutura da indústria alemã se caracterizava pela concentração e pela combinação, baseando-se "na aglutinação de diferentes grupos de produção, processamento e manufatura no interior das maiores e mais importantes unidades organizacionais de produção" (Gurland, 1941: 229). A saída encontrada pela economia alemã para superar a estagnação econômica que precedeu a chegada do nazismo ao poder foi a diversificação do escopo produtivo dentro das próprias plantas indus- 
triais, de modo a torná-las o mais polivalentes possível. Essa mudança qualitativa da produção na Alemanha é a verdadeira responsável pela recuperação econômica do país, enquanto o rearmamento, muitas vezes tomado como sua causa central, representa apenas um fator quantitativo. Pois os pedidos por ele originados "significam mais emprego, mas não significam emprego em uma nova base que altere as condições de retorno do capital investido" (Gurland, 1941: 228).

Em função dos altos custos que a renovação tecnológica implica e da insegurança acarretada por processos cujos resultados não é possível totalmente prever, os grandes conglomerados buscam subsídios, garantias e proteção do governo para levar adiante a inovação. O resultado dessa dinâmica é o fortalecimento, na Alemanha totalitária, do intervencionismo estatal, tanto na esfera da produção quanto na do mercado. Mas mesmo com tal incremento do poder de controle do Estado, Gurland pondera que não compartilha da visão que Pollock expressa em seu artigo publicado no mesmo número da revista, isto é, discorda que "isso signifique a abolição da economia de mercado" (Gurland, 1941: 232). Além de marcar posição quanto ao debate interno que tinha lugar no Instituto sobre o caráter do nazismo - se se tratava de uma forma de capitalismo ou de uma ordem nova -, Gurland põe em questão o anticapitalismo do qual faz uso a propaganda nacional-socialista. Mais do que um mero recurso demagógico, estaria em jogo um processo social de “'mediatização' da dependência”, que permite ao indivíduo atomizado ultrapassar sua "condição indefesa [defenselessness] e insegurança", de forma a se tornar "parte de um todo no qual lhe são dadas segurança e proteção" (Gurland, 1941: 243). ${ }^{10}$ Mobilizando a sensação de que existe algo maior - a figura do Estado totalitário - zelando pela segurança econômica da classe média, o nazismo, ao passo em que faz crer que fornece proteção contra os grandes poderes econômicos, nutre a esperança de que um dia também os pequenos poderão ascender.

O compromisso político vigente na Alemanha nacional-socialista congrega o aparato do partido e os grandes interesses empresariais - Big Business, como Gurland os chama. Enquanto a máquina partidária se incumbe de representar o clamor pela segurança, os monopólios zelam pela boa continuidade e pela expansão de seus negócios. A despeito dos conflitos que possam existir entre os dois pactuantes, a expansão econômica é um ponto convergente de ambos, na medida em que, sendo a própria meta dos conglomerados, é ao mesmo tempo o meio de prover segurança econômica à classe média mesmo que, contraditoriamente, esse processo implique espoliação e, no limite, destruição do pequeno capitalista. ${ }^{11}$ "A expansão garante a realização do motivo do lucro [profit motive] e o motivo do lucro estimula a expansão", motivo esse que propulsiona tanto as empresas privadas quanto as geridas pelo Estado (Gurland, 1941: 248). Expansão e aumento dos lucros se retroali- 
mentam. Gurland ressalta, assim, que o regime nazista não só se enquadra no interior do sistema capitalista, mas também se configura como um arranjo político-econômico que, promovendo a aceleração do processo de concentração, propiciando incentivo e garantias ao grande capital, introduzindo controle ${ }^{12}$ e organização, tudo isso tendo em vista sua contínua expansão, franqueia e favorece um brutal desenvolvimento econômico capitalista. Amidon e Worrell escrevem que, junto com Neumann e Kirchheimer, Gurland "enfatizava as continuidades entre o capitalismo monopolista e o fascismo", enquanto Pollock, por outro lado, "focalizava o predomínio político na economia nazista” (Amidon \& Worrell, 2008: 139-140).

\section{MARCUSE E A RACIONALIDADE TECNOLÓGICA}

Herbert Marcuse, em seu "Algumas implicações sociais da tecnologia moderna”, publicado também no número de 1941, trata da racionalização da vida ligada aos desenvolvimentos tecnológicos. O nacional-socialismo é aí encarado como um desdobramento específico do curso geral da evolução da civilização ocidental. Tecnologia é, para Marcuse, um processo social que inclui tanto a técnica propriamente dita quanto os indivíduos e grupos humanos. A técnica em si, diz Marcuse, pode "promover tanto autoritarismo quanto liberdade, tanto escassez quanto abundância, tanto a extensão quanto a abolição do trabalho árduo" (Marcuse, 1941: 414). A tecnologia, encarada como modo de produção, é ao mesmo tempo um instrumento de controle, de dominação, de manutenção ou de mudança de relações sociais. O nazismo se configura como um exemplo de que uma economia altamente mecanizada, racionalizada e produtivamente eficiente pode funcionar no sentido da opressão totalitária - conforme Marcuse, "uma forma de 'tecnocracia'” (Marcuse, 1941: 414). Ao afirmar que essa tecnocracia terrorista não pode ser atribuída exclusivamente aos esforços de uma economia de guerra, Marcuse faz referência ao artigo de Gurland ao escrever que "a economia de guerra é na verdade o estado normal do ordenamento nacional-socialista do processo social e econômico, e a tecnologia é um dos estímulos principais desse ordenamento" (Marcuse, 1941: 414).

A questão central posta pelo texto de Marcuse é a da disseminação de um novo tipo de racionalidade e de novos padrões de individualidade vinculados ao progresso tecnológico. Não se tratando de efeitos desse progresso sobre os indivíduos, as mudanças são, elas mesmas, "fatores determinantes no desenvolvimento da maquinaria e da produção em massa" (Marcuse, 1941: 415). O indivíduo da sociedade liberal era guiado pelo interesse próprio no ambiente da livre competição econômica e seu interesse individual era visto como racional, já que os produtos e efeitos desse interesse iriam de encontro 
às necessidades da sociedade. O processo econômico de concentração, o qual decorre da própria lógica da eficiência competitiva que crescentemente demanda racionalização e mecanização, solapa esse tipo de racionalidade individual, introduzindo em seu lugar o que Marcuse chama de racionalidade tecnológica. A racionalidade tecnológica está conectada ao ambiente social agora dominado pelo aparato - segundo o autor, o “termo 'aparato' [apparatus] denota as instituições, dispositivos e organizações da indústria em suas condições sociais predominantes" (Marcuse, 1941: 417). ${ }^{13}$ A racionalidade tecnológica é difusa e perpassa todas as relações sociais, "estabelece padrões de julgamento e promove atitudes que tornam os homens prontos a aceitar e mesmo introjetar os ditames do aparato" (Marcuse, 1941: 417). A antiga liberdade econômica da fase liberal dá lugar à tentativa de se tornar eficiente na execução de tarefas atribuídas, à adaptação ao poderio e aos desígnios dos conglomerados e monopólios: "O mundo foi racionalizado em tal medida, e tal racionalidade se tornou um tal poder social, que o indivíduo não pôde senão ajustar-se sem reservas" (Marcuse, 1941: 418).

Uma atitude de complacência com o factual, que Marcuse denomina matter-of-factness, ganha espaço. Segundo ele, Veblen teria sido um dos primeiros a identificar esse tipo de conduta. ${ }^{14} \mathrm{~A}$ atitude matter-of-factness "dissolve todas as ações numa sequência de reações semiespontâneas a normas mecânicas prescritas" (Marcuse, 1941: 419). Manipulando as máquinas, os homens aprendem a se ajustar a elas e a obedecer seu ritmo. Mas tal atitude, frisa Marcuse, não se restringe àqueles diretamente envolvidos na produção operando máquinas, mas "se propaga da ordem tecnológica para a ordem social" como um todo (Marcuse, 1941: 421). ${ }^{15}$ Crescentemente, as relações entre os homens são mediadas pelo mundo das máquinas, que passam a ser adoradas e a absorver a libido dos indivíduos - o "homem médio dificilmente se importa com qualquer ser vivo com a intensidade e persistência que ele mostra por seu automóvel" (Marcuse, 1941: 420). A racionalidade maquinal propiciada pelo aparato é a da adaptação dos meios aos fins prescritos, da economia de tempo e energia, da calculabilidade e antecipação de consequências: ${ }^{16}$ a razão se torna uma atividade de perpetuação do existente. O factual se torna racional. De força crítica, a razão se converte em poder de ajustamento, de conformidade, e os "indivíduos são despojados de sua individualidade, não por coerção externa, mas pela própria racionalidade sob a qual vivem" (Marcuse, 1941: 421). Marcuse opõe uma "verdade tecnológica" a uma "verdade crítica": o predomínio da racionalidade tecnológica tem significado a impotência e o declínio da razão crítica, em virtude tanto da expansão do aparato industrial e seu crescente controle sobre todas as esferas da vida quanto da tendência de incorporação de boa parte da oposição ao próprio aparato.

Com o ocaso do pensamento crítico, o "tipo predominante de indivíduo" passou "de uma unidade de resistência e autonomia [...] a uma de ductilidade 
[ductility] e ajustamento" (Marcuse, 1941: 428). Essa mudança de função explica a associação dos indivíduos em massas. Compostas de indivíduos isolados, as massas, nos regimes autoritários, intensificam ainda mais esse isolamento. O membro da massa se torna um "sujeito estandardizado da pura [brute] autopreservação" (Marcuse, 1941: 426). Marcuse aponta que, no contexto da sociedade de massa, os obstáculos socialmente colocados à perseguição do autointeresse tendem a ser tornar ineficazes, permitindo a liberação de impulsos agressivos, "desenvolvidos sob as exigências da escassez e da frustração" (Marcuse, 1941: 426). Os pensamentos, sentimentos e interesses dos indivíduos da massa são assimilados aos padrões do aparato. Daí que suas explosões de raiva "aterrorizantes e violentas", ao invés de ameaçarem o status quo, "são prontamente dirigidas aos competidores mais fracos e aos 'de fora' conspícuos (judeus, estrangeiros, minorias nacionais)" (Marcuse, 1941: 427). Pois as "massas organizadas não desejam uma nova ordem, mas uma participação maior na ordem existente", isto é, "lutam para corrigir, de uma forma anárquica, a injustiça da competição” (Marcuse, 1941: 427) - o que faz lembrar a proposição de Gurland de que o nazismo mobiliza as massas acenando a elas com a possibilidade de terem acesso a uma maior fatia do produto econômico.

A precipitação dos indivíduos na massa e o tipo de racionalidade que emana da grande empresa estão na raiz das tendências da racionalidade tecnológica. Essa racionalidade é, diz Marcuse, a forma madura da racionalidade individualista do sujeito da livre economia de mercado. Desenvolvendo-se como racionalidade da competição, na qual o interesse de mercado se sobrepõe ao interesse racional e a aquisição individual é absorvida pela eficiência, ela termina por resultar na "submissão estandardizada ao aparato que tudo abarca, que ela mesma criou" (Marcuse, 1941: 433). Mas, a essa altura, o aparato se desvencilha dos últimos vestígios da individualidade. "Esse foi o resultado lógico de um processo social que media a performance individual em termos de eficiência competitiva" (Marcuse, 1941: 433). Se a fase do individualismo liberal era marcada pela crença de que pedir ao indivíduo mais do que era sabido que ele podia realizar bem constituía algo essencial para seu desenvolvimento, "hoje o indivíduo é encarregado exatamente daquilo que ele pode, no momento, fazer bem" (Marcuse, 1941: 428).

Marcuse estabelece a ligação entre a emergência da democracia de massas moderna e o desenvolvimento da burocracia, apoiando-se para isso na sociologia da dominação burocrática apresentada por Weber em Economia e sociedade, a partir de sua afirmação de que, "em oposição à autoadministração democrática de pequenas unidades homogêneas", a burocracia é "um fenômeno que inevitavelmente acompanha [unvermeidliche Begleiterscheinung] a moderna democracia de massas" (Weber, 1985: 567). ${ }^{17}$ A burocracia, afirma Marcuse, "se torna o concomitante das massas modernas em virtude do fato 
de que a estandardização se processa conjuntamente com a especialização" (Marcuse, 1941: 430). A especialização demanda treinamento específico para funções particulares, o que, para Marcuse, conduz à atomização dos indivíduos especializados. A burocracia vem cumprir seu papel como instância coordenadora daquilo que está desarticulado.

Surgindo como um âmbito aparentemente objetivo e racional, que deriva da própria especialização racional das funções, a burocracia e sua racionalidade servem para "aumentar a racionalidade da dominação" (Marcuse, 1941: 431). ${ }^{18}$ A racionalidade tecnológica da burocracia faz com que ela se converta, frente às massas, em detentora da "dignidade universal da razão": "A racionalidade corporificada nas empresas gigantes faz parecer como se os homens, ao obedecê-las, obedecessem o ditame [dictum] de uma racionalidade objetiva" (Marcuse, 1941: 431). No caso da burocracia privada, essa aparência de objetividade faz com que os interesses particulares dos grupos capitalistas se apresentem como o interesse comum. Marcuse crê que tal mecanismo facilitou, nos países fascistas, a "fusão entre as burocracias privada, semiprivada (partido) e pública (governamental)" (Marcuse, 1941: 431). O diagnóstico de Marcuse sobre o nazifascismo aponta que sua origem reside na facilitação da obtenção de lucros para o grande capital: "A realização eficiente dos interesses das empresas de grande escala foi um dos motivos mais marcantes para a transformação do controle econômico em controle político totalitário, e eficiência é uma das principais razões para a manutenção do regime fascista face à sua população arregimentada" (Marcuse, 1941: 431). À semelhança de Neumann, Marcuse entende o nazismo como afiançador da acumulação monopolista e intensificador das contradições capitalistas - e, quanto ao primeiro aspecto, aproxima-se também das posições de Kirchheimer e Gurland.

\section{HORKHEIMER E AS TRANSFORMAÇÕES DO CAPITALISMO}

Já em 1937, no artigo "Teoria tradicional e teoria crítica" (ver Horkheimer, 1989), Max Horkheimer enxergava que se processara uma mudança estrutural no capitalismo. Essa transformação estrutural correspondeu à passagem do capitalismo liberal dos pequenos empresários autônomos do século XIX para, desde a virada para o século XX e suas primeiras décadas, um capitalismo monopolista controlado por managers que não são mais os proprietários dos meios de produção e sim somente diretores de grandes conglomerados. Esse processo, longe de acarretar efeitos apenas na esfera estritamente econômica, tem consequências que se espraiam para o "Estado e a sua organização de poder" (Horkheimer, 1989: 63): a influência dos managers e demais prepostos dos monopólios sobre a política é crescente. "No fim deste proces- 
so perdura uma sociedade não mais dominada por proprietários independentes, mas por camarilhas de dirigentes industriais e políticos" (Horkheimer, 1989: 64). O tema do declínio e, no limite, extinção da burguesia liberal e das instituições sobre as quais se assentava - o livre mercado, a família, as garantias jurídicas - está presente nas elaborações de Horkheimer desde pelo menos o final da década de $1930 .{ }^{19}$

Pouco depois do texto programático de 1937, seu artigo de 1939 sobre "Os judeus e a Europa" (ver Horkheimer, 1939-1940) aponta uma reorganização do aparelho estatal, com traços autoritários, comandada pelos chefes da indústria, do exército e da administração. Em "O Estado autoritário", publicado em 1942, Horkheimer afirma que o "capitalismo de Estado é o Estado autoritário do presente" (Horkheimer, 2000: 96). Suas formas são o reformismo, o bolchevismo e o fascismo. Referindo-se à União Soviética, Horkheimer escreve que a "forma mais consistente do Estado autoritário" é o "estatismo integral ou socialismo de Estado", pois que já "se libertou de qualquer dependência do capital privado" (Horkheimer, 2000: 101), atribuindo aos "países fascistas" a criação de uma "forma mista", na qual, a despeito de que, como no socialismo soviético, a "mais-valia é colocada sob controle do Estado e distribuída, flui [entretanto] sob o antigo nome de lucros em grandes quantidades para os magnatas industriais e proprietários de terra" (Horkheimer, 2000: 102). Pode-se considerar que Horkheimer também classificava o reformismo capitalista como uma forma mista (ver Wiggershaus, 2002: 309). Parecendo "uma paródia da sociedade sem classes" (Horkheimer, 2000: 114), o "capitalismo de Estado põe de lado o mercado e hipostasia a crise": a "moderna economia planejada é capaz de alimentar as massas melhor e ser melhor alimentada por elas do que pelos vestígios do mercado" (Horkheimer, 2000: 97, grifos meus). Em virtude das práticas que adota, o capitalismo de Estado se desembaraça de dificuldades no que diz respeito à administração da produção, às relações de intercâmbio entre cidade e campo e ao abastecimento dos grandes centros urbanos. "Cada vez mais, as questões econômicas estão se tornando questões técnicas" (Horkheimer, 2000: 105), afirma Horkheimer. No estágio do capitalismo de Estado, se, como escreve, "os antagonismos capitalistas [...] têm aumentado", estes "são hoje não só mais capazes de produzir liberdade, mas também menos capazes" (Horkheimer, 2000: 109).

Incluído no volume IX de Studies in Philosophy and Social Science, "O fim da razão" se inicia com um diagnóstico que cada vez mais se cristalizava nas mentes de Horkheimer e de Adorno: "Os conceitos fundamentais da civilização se encontram num processo de rápida decadência” (Horkheimer, 1941: 366). Um desses conceitos centrais é o de razão, cuja arma primeira é a crítica. Em função do modo como se desenvolveu no mundo burguês desde os gregos, a razão, "ao destruir fetiches conceituais, acabou destruindo a si própria" (Horkheimer, 1941: 367), a despeito de que poderia, por consistir na "faculdade de 
chamar as coisas pelo seu nome", ser "mais do que a vida alienada que preserva a si mesma na destruição dos outros e de si" (Horkheimer, 1941: 387). Já ganham corpo nesse texto de Horkheimer temas como o da razão como um instrumento e o da humanidade abandonada à autoconservação. A razão reduzida a um instrumento "tem os olhos fixos na vantagem, a frieza e a sobriedade como virtudes"; suas características "são a adaptação ótima dos meios aos fins, o pensamento como função poupadora de trabalho" (Horkheimer, 1997: 323). A contraface dessa razão atrofiada é o confinamento da existência humana à sua mera preservação. Horkheimer assinala que o "colapso da razão e o colapso da individualidade são um só e o mesmo" (Horkkheimer, 1941: 376).

O processo de solapamento do indivíduo é, em "O fim da razão" e em "Razão e autoconservação", como em outros textos de Horkheimer desse período, vinculado ao declínio do capitalismo concorrencial burguês e à ascensão dos monopólios. A era liberal teria, segundo Horkheimer, freado os ímpetos da autopreservação por meio da necessidade, socialmente dada, do estabelecimento de pactos entre seus agentes econômicos. Mas a monopolização "aboliu de novo essas restrições e conduziu a dominação social de volta a sua verdadeira natureza, a qual havia continuado a operar apenas onde a forma humana de dominação tinha deixado brechas para a inumanidade, nos pequenos rackets e rings das grandes cidades" (Horkheimer, 1941: 374).

\section{AdORNO E A CRÍTICA do PRESENTE COMO CRÍTICA DA HISTÓRIA ATÉ HOJE DECORRIDA}

Adorno escreveu "Reflexões sobre a teoria de classes" ao mesmo tempo em que preparava o que viria a ser uma das partes da Dialética do esclarecimento: "Já no final do verão de 1942 - durante uma viagem de Horkheimer a Nova York -, Adorno havia redigido uma primeira versão do capítulo sobre a cultura de massa, além de 'Reflexionen zur Klassentheorie'" (Wiggershaus, 2002: 354). Nesse texto, Adorno afirma que se fazia "necessário examinar de perto o conceito classe, de forma a que ele seja simultaneamente mantido [festgehalten] e modificado [verändert]" (Adorno, 2003a: 377). Não se deveria abrir mão dele na medida em que "sua base, a divisão da sociedade em exploradores e explorados, não apenas perdura sem ter sido diminuído, como também aumenta em coerção e solidez [Festigkeit]" (Adorno, 2003a: 377). Deveria, por outro lado, ser alterado "pois os oprimidos, hoje a enorme maioria da humanidade tal como previu a teoria, não podem experimentar a si mesmos como classe" (Adorno, 2003a: 377).

Em lugar da solidariedade, característica atribuída por Marx à classe explorada, ${ }^{20}$ Adorno destaca que, no presente, a conformidade frente ao exis- 
tente se afigura aos oprimidos como mais racional. "A organização total da sociedade pelo big business e sua técnica onipresente ocupou de forma tão completa o mundo e a ideia [Vorstellung] a ponto de tornar o pensamento de que as coisas poderiam ser diferentes um esforço quase sem esperança" (Adorno, 2003a: 376). Tendo como panorama político-econômico a escalada do processo de monopolização, Adorno escreve: "A história é, segundo a imagem da última fase econômica, a história dos monopólios. Segundo a imagem da usurpação manifesta, realizada hoje em comum acordo pelos líderes do capital e do trabalho, ela é a história das lutas de bandos, gangues e rackets" (Adorno, 2003a: 381). Ao diagnosticar que a "fase mais recente da sociedade de classes é dominada pelos monopólios", Adorno afirma que "ela impele para o fascismo, a forma de organização política que lhe faz jus" (Adorno, 2003a: 376).

Já no início do texto, Adorno expõe a compreensão da história que lhe serve de base. Para ele, o diagnóstico do presente se articula com toda a história decorrida no sentido de que a "forma mais recente do injusto sempre lança luz sobre o todo" (Adorno, 2003a: 374). Adorno está retomando aí a proposição das teses sobre a história de Benjamin acerca da aproximação entre constelações do presente e do passado a partir das exigências do presente. Assim, o presente dominado pelos monopólios ilumina a história da dominação em sua totalidade. Mas não só isso: a figura atual da dominação é herdeira, produto e continuadora de formas anteriores de opressão. Aqui é possível pensar naquilo que Benjamin chama de "contínuo da história" (Benjamin, 2005: 119, 123 e 128) - o qual, segundo ele, a recuperação de momentos revolucionários faz explodir. Segundo Adorno, as "leis da troca não conduziram à forma mais recente de dominação como a forma histórica adequada da reprodução da sociedade como um todo no presente estágio, mas sim a antiga dominação entrou no aparato econômico para, uma vez com total disposição sobre ele, destroçá-lo e facilitar a vida para si" (Adorno, 2003a: 381). Identificar que o novo é uma outra roupagem do velho mito é fundador da própria crítica: "Só quem reconhece o mais novo como igual estará a serviço daquilo que seria diferente" (Adorno, 2003a: 376). A essa altura, Adorno já está textualmente propondo que a crítica da economia política teria uma dimensão de "crítica da história como um todo" (Adorno, 2003a: 373). Na medida em que "toda opressão que os homens infligiram aos próprios homens culmina na modernidade, na fria miséria do trabalho assalariado livre, o decorrer histórico se revela em condições e coisas [...] como traço [Spur] do antigo sofrimento" (Adorno, 2003a: 373-374).

A fase liberal, à qual a ascensão dos monopólios vem dar fim, não pode ser inteiramente compreendida sob o prisma da livre concorrência entre os capitalistas: o êxito dos capitalistas sempre se lastreou no "antigo e novo roubo dos conquistadores, na afiliação com a propriedade feudal, que a eco- 
nomia concorrencial nunca liquidou de verdade, na relação direta com o aparato militar de dominação", ao lado do fato de que seu grau de sucesso depende da "força do capital com a qual entram na concorrência, do poder político e social que representam" (Adorno, 2003a: 378). A assim chamada igualdade da concorrência revela desse modo seu conteúdo de inverdade: o resultado dela se apresenta como derivado da continuação de formas anteriores do injusto. No que diz respeito à burguesia, a verdade do conceito de classe reside na particularidade de interesses que a une; a inverdade consiste na própria não unidade da classe. Por um lado, os proprietários podem exercer sua opressão enquanto classe una sobre os sem-propriedade, mas, por outro, os mais fortes dentre eles subjugam os outros membros menos poderosos. Com os monopólios, diz Adorno, a "dominação de classe se prepara para sobreviver à forma anônima, objetiva, da classe" (Adorno, 2003a: 377). Mas se na economia de mercado "a inverdade era latente no conceito de classe", no período monopolista "ela se tornou tão visível quanto sua verdade, a sobrevivência das classes, invisível” (Adorno, 2003a: 379).

Adorno afirma que o prognóstico de Marx sobre a divisão da sociedade entre poucos proprietários e uma massa de não proprietários se confirmou, mas "ao invés de que com isso a essência da sociedade de classe se tornasse evidente, ela foi enfeitiçada pela sociedade de massa, na qual a sociedade de classe culminou" (Adorno, 2003a: 380). Nessa sociedade de massas, a "classe dominante desaparece detrás da concentração do capital" (Adorno, 2003a: 380). O período monopolista traz consigo uma melhoria do padrão de vida da população, que é "pago com rendimentos ou lucros dos monopólios" (Adorno, 2003a: 385). A divisão da sociedade entre dominantes e dominados não se consuma pois com a depauperação dos últimos; pelo contrário, esses experimentam uma elevação de seus níveis de reprodução. O elemento da vontade consciente dos dominantes atravessa o texto de Adorno, que afirma que a melhora do padrão de vida se deve antes à "autoconsciência do sistema quanto às condições de sua perpetuação" do que à "matemática inconsciente do esquema" (Adorno, 2003a: 386). Adorno frisa que o padrão de vida mais elevado não significa incremento do poder (Macht) dos dominados, e sim aumento de sua impotência (Ohnmacht). A "impotência política e social" converte "todos os homens em meros objetos administrados [Verwaltungsobjekten] dos monopólios e seus Estados" (Adorno, 2003a: 386). É tal impotência que "permite a condução da guerra em todos os países" (Adorno, 2003a: 386).

A impotência atende pelo nome de desumanização (Entmenschlichung). Sob o monopólio, o processo de desumanização se aperfeiçoa como reificação (Verdinglichung), em lugar de se dar pela mera força bruta. Para Adorno, a desumanização não é algo que vem de fora e coloniza os homens, e sim um processo que integra a própria formação das pessoas; não está em jogo para ele a ideia de influenciar a opinião, tal como pareceria aos liberais ser o caso, 
mas de que já a cultura de massas "simplesmente os faz [os homens] sempre o que já são graças à coerção do sistema” (Adorno, 2003a: 390). A desumanização é "precisamente a imanência dos oprimidos no sistema" (Adorno, 2003a: 391). Ainda que Adorno se oponha à tese de que a crescente divisão do trabalho impede que o trabalhador entenda o todo, assevere que a distinção entre trabalhadores e engenheiros se assenta mais no privilégio do que no efetivo domínio do processo produtivo, diz que o processo de trabalho que entendem os molda ainda mais do que aquele que não entendiam, tornando-se um “'véu tecnológico"” (Adorno, 2003a: 390). A despeito disso, termina o texto dizendo que a "reificação tem seu limite nos homens reificados" (Adorno, 2003a: 391). Com o horror do nazismo - Adorno se refere a ele como "a ditadura que se pode ver [sehenden Diktatur]" (Adorno, 2003a: 391) -, o encanto da economia como destino inelutável pode ser quebrado.

\section{SOB A ESTRELA CHAMADA BENJAMIN}

Em meados de 1942, o Instituto publica em edição privada um livro de escritos em memória de Walter Benjamin, Walter Benjamin zum Gedächtnis, no qual aparecem suas teses sobre a história - que Hannah Arendt havia levado da França para os Estados Unidos e entregue a Adorno -, além de um artigo de Adorno, "George e Hofmannstahl" (ver Adorno, 2003b), e dois textos de Horkheimer, "O Estado autoritário" e "Razão e autoconservação" (ver Horkheimer, 1997). A revista do Instituto, a essa altura publicada em inglês, trouxe em seu número de 1941 o ensaio "O fim da razão", de Horkheimer. Se comparados frase a frase, o texto alemão de "Razão e autoconservação" se revela uma versão, acrescida de alguns novos desdobramentos, do artigo em inglês "O fim da razão". Os textos de Horkheimer e o de Adorno publicados em Walter Benjamin zum Gedächtnis não são meras homenagens à memória de Benjamin. Rolf Wiggershaus faz notar uma passagem curiosa: "Todos aqueles a quem Horkheimer deu o volume disseram que 'Vernunft und Selbsterhaltung' [Razão e autoconservação] e 'George und Hofmannstahl' [George e Hofmannstahl] eram os melhores trabalhos que Benjamin escrevera - melhores até do que Thesen über den Begriff der Geschichte [Teses sobre o conceito da história]" (Wiggershaus, 2002: 341). "O Estado autoritário" traz uma formulação totalmente embebida do espírito das teses de Benjamin: Horkheimer diz que o fim da exploração "não é uma maior aceleração do progresso, mas um salto qualitativo para fora da dimensão do progresso" (Horkheimer, 2000: 107). Em "Reflexões sobre a teoria de classes", que também em 1942 Adorno escreveu, já se encontra a ideia fundamental, tributária de Benjamin, de que é necessário alargar a crítica da dominação para uma crítica de toda a história decorrida. 
Em carta de Adorno a Horkheimer, na qual dizia que "devemos publicar o manuscrito", pode-se ler sobre as teses de Benjamin: "Trata-se da última concepção de Benjamin. Sua morte torna inúteis os escrúpulos causados por seu caráter provisório. Não se pode duvidar da grande classe do conjunto. Além disso, nenhum dos outros trabalhos de Benjamin o revela tão próximo de nossas próprias intenções" (Adorno \& Horkheimer, 2004: 144 [carta de Adorno a Horkheimer, New York, 12/06/1941]). A resposta de Horkheimer foi: "Estou tão feliz quanto você por nos ver de posse das teses de Benjamin sobre a história. Elas vão nos ocupar ainda por muito tempo, e ele estará presente a nosso lado. A identidade de barbárie e cultura [...] constituiu, aliás o tema de uma de minhas últimas conversas com ele num café na estação de Montparnasse" (Adorno \& Horkheimer, 2004: 155 [carta de Horkheimer a Adorno, Pacific Palisades, 23/06/1941]). A parceria de Adorno e Horkheimer, que pouco tempo depois resultou na Dialética do esclarecimento, pode ser em larga medida pensada "sob a estrela que chamava-se Benjamin" (Wiggershaus, 2002: 339-340).

\section{ESBOÇO DE UMA CONCLUSÃO: A DIALÉTICA DO ESCLARECIMENTO E A CRÍTICA CIVILIZATÓRIA}

Grosso modo, as posições no debate de 1941 em Columbia poderiam ser divididas em dois grandes grupos: de um lado, a conclusão de que o capitalismo havia passado por transformações tão grandes a ponto de uma nova ordem estar se estabelecendo, o capitalismo de Estado; de outro, a descrição do sistema capitalista da época como uma forma totalitária de economia monopolista. Enquanto Pollock defendeu a primeira interpretação, Neumann sustentou a segunda. Os outros participantes, Kirchheimer, Gurland e Marcuse, tendiam a concordar mais com Neumann do que com Pollock. Esse debate precedeu a elaboração da Dialética do esclarecimento de Adorno e Horkheimer, que apresenta ainda uma outra explicação. Se os textos de Horkheimer dos anos 1930 ainda lançavam mão de uma interpretação marxista em alguma medida mais "clássica" do capitalismo, no final dessa década e início dos anos 1940 sua posição muda. Essa mudanças têm a ver com o trabalho conjunto com Adorno no que deveria ser um livro sobre a dialética e com o enorme impacto das teses sobre a história de Benjamin. Desde pelo menos o começo da década de 1940, pode-se acompanhar uma ênfase crescente em uma crítica do processo civilizatório, largamente influenciada pela concepção de Benjamin da história como um contínuo de dominação, nos textos de Adorno e Horkheimer, como "O fim da razão" (1941), "Razão e autoconservação" (1942) e "O Estado autoritário" (1942), de Horkheimer, e "Reflexões sobre a teoria de classes" (1942), de Adorno.

No final de 1941, vindo de Nova York, Adorno havia chegado à Califórnia para juntar-se a Horkheimer. No período que antecede à sua mudança, 
houve uma fértil troca de cartas, na qual é possível observar as crescentes afinidades eletivas entre os dois com respeito ao delineamento do projeto comum que pretendiam levar a cabo. Por meio de sua correspondência, é possível ver que os objetivos de ambos foram convergindo para a análise crítica dos rumos do processo civilizacional e de seus malogros. O resultado desse projeto, Dialética do esclarecimento, condensa os esforços de ambos no que diz respeito à elaboração de uma explicação para o presente histórico e pode ser considerado como uma Aufhebung ${ }^{21}$ do debate de Columbia de 1941. Se Dialética do esclarecimento tem por pano de fundo as discussões havidas em Columbia e no âmbito da revista do Instituto, com vistas a apresentar uma resposta à questão "como o nacional-socialismo foi possível?" o livro não aceita inteiramente nenhuma das explicações até então apresentadas e se dirige para uma crítica do próprio processo civilizatório. Ao fazê-lo, sugere, mais ou menos explicitamente, que a crítica da economia política não é suficiente para dar conta da barbárie e da reiterada recaída da humanidade nessa barbárie. O livro apresenta como seu objetivo entender "por que a humanidade, em vez de entrar em um estado verdadeiramente humano, se afunda em uma nova espécie de barbárie" (Horkheimer \& Adorno, 1947: 5).

Apreender como o "progresso [Fortschritt] se transforma em regressão [Rückschritt]" (Horkheimer \& Adorno, 1947: 10) exige uma abordagem distinta daquelas que se ocupam exclusivamente com a configuração do Estado, os compromissos políticos e os movimentos da economia. Dialética do esclarecimento procura executar o programa de "mostrar como, apesar de todos os desvios e resistências, a dominação consequente da natureza sempre se impõe mais resolutamente e integra toda a interioridade humana. Desse ponto de vista, deveriam ser deduzidas também as formas da economia, da dominação, da cultura" (Horkheimer \& Adorno, 1947: 265). Esse trecho se encontra em notas, muitas vezes constituídas de pequenos aforismos, colocadas pelos autores ao final do livro, pois no decorrer dele elas não teriam encontrado seu lugar. A maioria desses esboços, afirmam, diz respeito a uma "antropologia dialética" (Horkheimer \& Adorno, 1947: 12). Penso poder afirmar que antropologia dialética é um nome usado por Adorno e Horkheimer para se referir a sua crítica civilizacional.

Para eles, a investigação de um fenômeno como o nacional-socialismo, longe de se ocupar apenas com as transformações no capitalismo nos últimos decênios, implica em pensar criticamente o processo do Esclarecimento. Essa é a viragem muito significativa realizada pelo livro. Esclarecimento, desde logo, é entendido por Adorno e Horkheimer num sentido mais amplo do que o usual: conforme os autores, "as linhas da razão, da liberalidade, da civilidade se estendem incomparavelmente mais longe do que supõe a representação da história que data o conceito do burguês apenas a partir do fim do feudalismo medieval" (Horkheimer \& Adorno, 1947: 60). O início do processo 
do Esclarecimento está já na atribuição de nomes às coisas e aos eventos da natureza que amedrontavam e não possuíam explicação. Com efeito, nomear permite dominar o desconhecido por meio do nome. Os mitos, que procuravam "relatar, denominar, dizer a origem, mas também expor, fixar, explicar" (Horkheimer \& Adorno, 1947: 18), já são uma etapa do próprio Esclarecimento.

Guardadas todas as diferenças existentes entre as distintas formas pelas quais o fazem, tanto o mito quanto a ciência visam à dominação da natureza: "O que os homens querem aprender da natureza é como empregá-la para dominar completamente a ela e aos homens. Nada mais importa" (Horkheimer \& Adorno, 1947: 14). Adorno e Horkheimer identificam como um problema central a ausência de autoconsciência no que diz respeito à crescente dominação no âmbito do natural e do social. A dominação do mundo ao redor adquire um caráter cego e passa a ter como critério único o cálculo entre meios e fins. O processo civilizatório, buscando livrar os homens do jugo da natureza, estabelece para eles condições tão petrificadas que acabam por se assemelhar àquelas do âmbito do natural: "A civilização é a vitória da sociedade sobre a natureza, que transforma tudo em pura natureza" (Horkheimer \& Adorno, 1947: 219).

A dominação da natureza deriva do esforço de autoconservação. A origem do processo civilizatório está na persecução da autoconservação, e isso desde logo confere a esse processo seu sentido. Os fins da autoconservação conduzem ao desenvolvimento de uma razão calculadora, abstrata, que pode ser considerada o motor do processo civilizatório. O livro vê o desdobrar de uma razão abstrata, já na magia, passando pela religião, até chegar à moderna ciência. Essa razão abstrata antecede a troca de equivalentes, a qual, ao surgir e desenvolver-se, por sua vez intensifica e impulsiona a razão abstrata. Sendo historicamente anterior à troca mercantil, ela constituiu um fator decisivo para que esta última tenha se generalizado. Dialética do esclarecimento pode ser compreendida como uma tentativa de explicar o seguinte entrelaçamento: a dominação da natureza e a autoconservação geraram uma razão abstrata que faz com que o processo civilizatório não vá além da mera dominação, de modo que a sociedade se reproduz continuamente como uma forma de dominação. Afirmando que a "técnica efetua a adaptação ao inanimado a serviço da autoconservação, não mais como a magia, através da imitação corporal da natureza externa, mas através da automatização dos processos [Prozesse] espirituais, através de sua transformação em processos [Abläufe] cegos" (Horkheimer \& Adorno, 1947: 214), Adorno e Horkheimer concluem que a "racionalidade técnica hoje é a racionalidade da própria dominação" (Horkheimer \& Adorno, 1947: 145).

O nazismo não é um desvio da civilização ocidental, mas sim a radicalização de suas tendências de dominação social, a consumação de sua irracionalidade intrínseca. O antissemitismo mobilizado pelo ticket fascista é 
um pretexto que permite dar vazão à revolta dos indivíduos contra a civilização, funcionando, porém, paradoxalmente, no sentido de incrementar a própria dominação à qual estão submetidos. Nos países assim chamados democráticos, essas tendências igualmente estariam presentes, assim como nada permitiria dizer que a União Soviética encontrar-se-ia subtraída dessa mesma lógica. É então inteiramente correto afirmar, como faz Silvia Schwarzböck, que a "sociedade de massas que nos Estados Unidos pôde ser governada por Roosevelt forma parte do mesmo processo de ilustração que a sociedade de massas que na Alemanha foi governada por Hitler. [...] A racionalidade que tornou possível a indústria do entretenimento é a mesma que construiu os campos de concentração" (Schwarzböck, 2008: 102). Para Adorno e Horkheimer, as sociedades democráticas de massas, a Alemanha nazista e o sistema soviético eram filhos legítimos da Aufklärung. Uns e outros faziam uso da mesma racionalidade técnica que, com o processo de monopolização e a planificação, se espraiou amplamente e que, longe de apontar para a emancipação social e conduzir a sociedade a um estágio melhor, reforçou a dominação. ${ }^{22}$ Esse é o sentido do progresso que se converte em regressão, aí está a chave para entender por que "a terra totalmente esclarecida brilha sob o signo de uma triunfal calamidade [Unheils]" (Horkheimer \& Adorno, 1947: 13).

Recebido em 20/03/12| Aprovado em 23/01/13

Ricardo Pagliuso Regatieri é doutorando no Programa de Pós-Graduação em Sociologia da Universidade de São Paulo (PPGS/USP), onde é bolsista da Fundação de Amparo à Pesquisa do Estado de São Paulo (FAPESP). Atualmente realiza um período sanduíche na Goethe-Universität Frankfurt com bolsa do DAAD. É autor de Negatividade e ruptura: configurações da crítica de Robert Kurz (2012). Suas principais áreas de interesse são teoria sociológica, sociologia alemã e teoria crítica. 


\section{NOTAS}

1 Já em 1934, em seu balanço da sociologia alemã do período de Weimar, Mannheim aponta a fecundidade do "estudo científico de eventos contemporâneos (Gegenwartskunde), do qual muito é esperado", levado a cabo pela "interessante Zeitschrift für Sozialforschung" (Mannheim, 1953: 223).

2 Entre novembro e dezembro de 1941, foram apresentadas em Columbia as seguintes conferências: "Estado e indivíduo sob o nacional-socialismo", por Herbert Marcuse, "Propriedade privada sob o nacional-socialismo", por Arcadius R. L. Gurland, "Os novos governantes na Alemanha”, por Franz Neumann, "A ordem legal do nacional-socialismo", por Otto Kirchheimer, e "O nacional-socialismo é uma nova ordem?", por Friedrich Pollock. Os textos das conferências de Kirchheimer e Pollock foram publicados na edição de 1941 da revista do Instituto (ver Kirchheimer, 1941b; Pollock, 1941b), que ainda trazia outro de cada um deles - "Capitalismo de Estado: suas possibilidades e limitações", de Pollock (ver 1941a), e "Mudanças na estrutura do compromisso político", de Kirchheimer (ver 1941a). Se as conferências de Marcuse, Gurland e Neumann não chegaram a integrar a edição, os dois primeiros dela participaram com os artigos "Algumas implicações sociais da tecnologia moderna" (ver Marcuse, 1941) e "Tendências tecnológicas e estrutura econômica sob o nacional-socialismo" (ver Gurland, 1941).

3 Nos Estados Unidos, a Zeitschrift für Sozialforschung, órgão de difusão dos textos dos pesquisadores do Institut für Sozialforschung, passa a ser publicada como Studies in Philosophy and Social Science e o instituto a se chamar Institute of Social Research. A "revista Studies in Philosophy and Social Science" sucedeu a Zeitschrift für Sozialforschung "no fim de 1939" (Jay, 2008: 202). "Devido à declaração de guerra e à transferência do local de edição da revista de Paris para Nova York, a revista parou de ser publicada durante quase um ano antes que a Zeitschrift für Sozialforschung fosse substituída por Studies in Philosophy and Social Science" (Wiggershaus, 2002: 294).

4 Em nota de rodapé nessa página, Pollock escreve: "O termo 'modelo' é usado aqui no sentido do 'tipo ideal' de Max Weber". 
5 "A forma totalitária de capitalismo de Estado é uma ameaça mortal para todos os valores da civilização ocidental. Aqueles que querem manter esses valores devem compreender plenamente as possibilidades e limitações do agressor para que sua resistência tenha sucesso. Além disso, eles devem ser capazes de mostrar de que maneira os valores democráticos podem ser mantidos sob as condições em mudança" (Pollock, 1941a: 200).

6 No início desse texto, Pollock frisa: "Meu objetivo é evidenciar a nova ordem como um novo sistema social e econômico em contraste com o capitalismo monopolista" (Pollock, 1941b: 440).

7 Jay se refere ao artigo "Die gegenwärtige Lage des Kapitalismus und die Aussichten einer planwirtschaftlichen Neuordnung" ("A situação atual do capitalismo e as perspectivas de uma nova ordem econômica planificada").

8 "A dominação política é alcançada, por um lado, pelo terror organizado e pela propaganda esmagadora e, por outro, pelo pleno emprego e um padrão adequado de vida para todos os grupos-chave, a promessa de segurança e de uma vida mais abundante para todos que se submetem voluntariamente e completamente. Esse sistema está longe de ser baseado apenas na força bruta" (Pollock, 1941a: 223). Ver, também, Pollock (1941b: 452-453).

9 Já no período imperial, Neumann destaca que uma questão central ao redor do qual se debatia a Alemanha era a da "expansão imperialista por meio da guerra" (Neumann, 2009: 3).

10 Nesse ponto, Gurland remete à, e se serve da, abordagem de Kirchheimer acerca da crescente anulação dos indivíduos e predomínio dos grupos.

11 "Apesar de resultar do conjunto das condições econômicas, o desenvolvimento que tem tido lugar desde 1933 não foi de modo algum automático. As tendências que desde então têm tomado forma definitiva não se afiguraram igualmente necessárias e desejáveis a todas as partes que compõem o quadro" (Gurland, 1941: 240).

12 O Estado totalitário, se munido de mais meios para controlar a economia, é, por outro lado, incapaz de exercer total controle sobre ela (ver Gurland, 1941: 249). 
13 O termo Apparat é recorrente no vocabulário de Weber em Economia e sociedade, sendo usado para designar o aparato burocrático [bürokratischer Apparat] ou aparato de dominação burocrática [bürokratischer Herrschaftsapparat]. Ver Weber (1985: 551-579).

14 Marcuse está se referindo a The instinct of workmanship: and the state of industrial arts, livro de Thorstein Veblen publicado em 1914. Nele, Veblen busca analisar o papel da indústria e da tecnologia em diferentes estágios da civilização, desde o mundo primitivo até a moderna produção baseada na maquinaria.

15 A esse respeito, caberia remeter aqui ao "caráter contemplativo" tal como o define Lukács em História e consciência de classe (Lukács, 2003: 218). O caráter contemplativo do sujeito pode ser descrito como aquela atitude de apenas acompanhar o desenrolar das leis que regem a vida no capitalismo, que parecem imutáveis, e de se adaptar a elas, de se ajustar ao mundo assim como é dado. Ao contrário de Veblen, que, procurando descrever a submissão ao factualmente dado trata, de modo por certo distinto de Lukács, do mesmo fenômeno, o autor húngaro não é citado por Marcuse.

16 Marcuse afirma que a ideia de eficiência propugnada pela administração científica de Frederick Taylor "ilustra perfeitamente a estrutura da racionalidade tecnológica" (Marcuse, 1941: 422). Buscando explicar a doutrina taylorista, Robert F. Hoxie diz que a administração científica "substitui a suposição [guesswork] pelo conhecimento exato" (Hoxie apud Marcuse, 1941: 422). Vale lembrar que, para o modelo do capitalismo de Estado de Pollock, a suplantação do guesswork pela previsão e pelo cálculo constitui um traço central.

17 Sobre a sociologia da burocracia, ver especialmente Weber (1985: 551-579).

18 Weber escreve: "O destino material das massas depende do funcionamento contínuo e correto das organizações capitalistas privadas crescentemente ordenadas de forma burocrática [...]" (Weber, 1985: 570). E se porventura o aparato de dominação [Herrschaftsapparat] "suspende seu trabalho ou se detém por uma força poderosa, a consequência é um caos, para dar fim ao qual dificilmente podem 
os dominados improvisar um substituto. Isto se refere tanto à esfera da administração econômica pública quanto à da privada" (Weber, 1985: 570).

19 "A característica essencial do período de capitalismo de Estado é a eliminação da esfera da distribuição e da circulação ou - expresso em termos filosóficos - da mediação. Para uma apreciação crítica da sociedade burguesa, isso possui um significado fundamental porque, na esfera da mediação, conceitos como igualdade e liberdade têm sua base social objetiva. Estes agora se tornam historicamente obsoletos" (Demirović, 1999: 86). No primeiro parágrafo de "O Estado autoritário", lê-se: "O El Dorado da existência burguesa, a esfera da circulação, está sendo liquidada" (Horkheimer, 2000: 95).

20 É à teoria de classes de Marx que está se referindo Adorno quando fala da teoria que previra a experiência e a solidariedade da classe explorada.

21 Isto é, uma superação que, ao mesmo tempo, conserva e carrega consigo elementos daquilo que é superado.

22 É importante destacar que, para Adorno e Horkheimer, os desdobramentos da técnica não devem ser atribuídos "a nenhuma lei de evolução [Bewegungsgesetz] da técnica enquanto tal, mas à sua função na economia hoje" (Horkheimer \& Adorno, 1947: 145). 


\section{REFERÊNCIAS BIBLIOGRÁFICAS}

Adorno, Theodor W. (2003a) [1969]. Reflexionen zur Klassentheorie [1942]. In: Gesammelte Schriften, Band 8. Frankfurt am Main: Suhrkamp.

Adorno, Theodor W. (2003b) [1969]. George und Hofmannstahl. Zum Briefwechsel [1942]. In: Gesammelte Schriften, Band 10.2. Frankfurt am Main: Suhrkamp.

Adorno, Theodor W. \& Horkheimer, Max. (2004). Briefe und Briefwechsel - Band 4: Theodor W. Adorno/Max Horkheimer. Briefwechsel 1927-1969. Band 4.II: 1938-1944. Frankfurt am Main: Suhrkamp.

Amidon, Kevin S. \& Worrell, Mark P. (2008). A. R. L. Gurland, the Frankfurt School, and the critical theory of antisemitism. Telos, 144, p. 129-147.

Benjamin, Walter. (2005) [2001]. Sobre o conceito de história [1940]. In: Löwy, Michael (org.). Walter Benjamin: aviso de incêndio: uma leitura das teses "Sobre o conceito de história”. São Paulo: Boitempo.

Demirović, Alex. (1999). Der nonkonformistische Intellektuelle: Die Entwicklung der Kritischen Theorie zur Frankfurter Schule. Frankfurt am Main: Suhrkamp.

González, Francisco Colom. (1992). Las caras del Leviatán: Una lectura política de la teoría crítica. Barcelona: Anthropos. Gurland, Arcadius R. L. (1941). Technological trends and economic structure under National Socialism. Studies in Philosophy and Social Science, IX, p. 226-263.

Horkheimer, Max. (2000) [1978]. The authoritarian State [1942]. In: Arato, Andrew \& Gebhardt, Eike (orgs.). The essential Frankfurt School reader. Nova York: Continuum, p. 95-117.

Horkheimer, Max. (1997). Vernunft und Selbsterhaltung [1942]. In: Gesammelte Schriften, Band 5. Frankfurt am Main: Fischer, p. 320-350.

Horkheimer, Max. (1989). Teoria tradicional e teoria crítica [1937]. In: Horkheimer, Max \& Adorno, Theodor W. Textos Escolhidos - Max Horkheimer, Theodor W. Adorno. São Paulo: Nova Cultural (Coleção Os Pensadores).

Horkheimer, Max. (1941). The end of reason. Studies in Philosophy and Social Science, IX, p. 366-388. 
Horkheimer, Max. (1939-1940). Die Juden und Europa. Studies in Philosophy and Social Science, VIII, p. 115-137.

Horkheimer, Max \& Adorno, Theodor W. (1947). Dialektik der Aufklärung. Philosophische Fragmente. Amsterdam: Querido.

Jay, Martin. (2008) [1973]. A imaginação dialética: história da Escola de Frankfurt e do Instituto de Pesquisas Sociais, 1923. 1950. Rio de Janeiro: Contraponto.

Kirchheimer, Otto. (1941a). Changes in the structure of political compromise. Studies in Philosophy and Social Science, IX, p. 264-289.

Kirchheimer, Otto. (1941b). The legal order of National Socialism. Studies in Philosophy and Social Science, IX, p. 456-475. Lukács, Georg. (2003) [1923]. História e consciência de classe: estudos sobre a dialética marxista. São Paulo: Martins Fontes. Mannheim, Karl. (1953) [1934]. German sociology (19181933). In: Essays on sociology and social psychology. Londres: Routledge \& Kegan Paul Ltd.

Marcuse, Herbert. (1941). Some social implications of modern technology. Studies in Philosophy and Social Science, IX, p. 414-439.

Neumann, Franz. (2009) [1944]. Behemoth: the structure and practice of National Socialism, 1933-1944. Chicago: Ivan R. Dee Publisher.

Pollock, Friedrich. (1941a). State Capitalism: its possibilities and limitations. Studies in Philosophy and Social Science, IX, p. 200-225.

Pollock, Friedrich. (1941b). Is National Socialism a new order? Studies in Philosophy and Social Science, IX, p. 440-455. Pollock, Friedrich. (1932). Die gegenwärtige Lage des Kapitalismus und die Aussichten einer planwirtschaftlichen Neuordnung. Zeitschrift für Sozialforschung, I, p. 8-27.

Postone, Moishe \& Brick, Barbara. (1993). Critical theory and political economy. In: Benhabib, Seyla; Bonß, Wolfgang \& McCole, John (orgs.). On Max Horkheimer: new perspectives. Cambridge: The MIT Press, p. 215-256.

Postone, Moishe \& Brick, Barbara. (1982). Critical pessimism and the limits of traditional marxism. Theory and Society, 11/5, set., p. 617-658. 
Schwarzböck, Silvia. (2008). Adorno y lo político. Buenos Aires: Prometeo Libros.

Veblen, Thorstein. (1918) [1914]. The instinct of workmanship and the state of industrial arts. Nova York: B. W. Huebsch.

Weber, Max. (1985) [1922]. Wirtschaft und Gesellschaft. Grundriss der verstehenden Soziologie. Tübingen: Mohr.

Wiggershaus, Rolf. (2002) [1986]. A Escola de Frankfurt: história, desenvolvimento teórico, significação política. Rio de Janeiro: Difel.

Worrell, Mark P. (2006). The other Frankfurt School. Fast Capitalism, 2/1. Disponível em <http://www.fastcapitalism. com>. Acesso em 16 jun. 2012. 
Palavras-chave

Teoria crítica;

Nazismo;

Capitalismo de estado; Capitalismo monopolista; Crítica civilizacional.

Keywords

Critical theory; National Socialism; State capitalism;

Monopoly capitalism; Critique of the process of civilization.
SOBRE A NATUREZA DO PRESENTE HISTÓRICO. A CRÍTICA DA DOMINAÇÃO NO INSTITUTO DE PESQUISA SOCIAL NO INÍCIO DOS ANOS 1940

\section{Resumo}

$\mathrm{O}$ artigo procura reconstruir as posições de membros do Instituto de Pesquisa Social em uma série de conferências levadas a cabo em 1941 durante seu exílio nos Estados Unidos a respeito da caracterização do presente histórico, marcado pelo nacional-socialismo, pelo sistema soviético e pelo capitalismo norte-americano. Em seguida, busca apontar de que maneira Dialética do esclarecimento, de Max Horkheimer e Theodor Adorno, responde às mesmas questões que suscitaram o debate de 1941, mas a partir já de um ponto de vista distinto, nomeadamente o de uma crítica do processo civilizatório como forma de dar conta do horror e da barbárie.

\section{ON THE NATURE OF THE HISTORICAL PRESENT. A} CRITIQUE OF DOMINATION AT THE INSTITUTE OF SOCIAL RESEARCH IN THE BEGINNING OF THE 1940'S

\section{Abstract}

The article seeks to reconstruct the positions of members of the Institute of Social Research within a series of conferences carried out in 1941 during their exile in the United States, which addressed the historical present marked by National Socialism, the Soviet System and North American capitalism. It then points out how Max Horkheimer's and Theodor Adorno's Dialectic of enlightenment offers an answer to the same questions that originated the debate of 1941, but from a different point of view, namely that of a critique of the process of civilization as a form of dealing with horror and barbarism. 